\title{
Salivary profile and dental status of patients with multiple sclerosis
}

\section{Profil ślinowy i stan uzębienia pacjentów ze stwardnieniem rozsianym}

\author{
Hamed Mortazavi ${ }^{\mathrm{i}, \mathrm{A}, \mathrm{F}}$, Mona Akbari ${ }^{2, B}$, Mohammad Ali Sahraiann ${ }^{3, B}$, Ali Alborzi Jahromi ${ }^{4, B}$, Shervin Shafiej ${ }^{5, D}$ \\ ${ }^{1}$ Department of Oral Medicine, School of Dentistry, Shahid Beheshti University of Medical Sciences, Tehran, Iran \\ ${ }^{2}$ Department of Periodontics, School of Dentistry, Qazvin University of Medical Sciences, Iran \\ ${ }^{3}$ Department of Neurology, Neuroscience Institute, MS Research Center, Tehran University of Medical Sciences, Iran \\ ${ }^{4}$ Department of Prosthodontics, School of Dentistry, Qazvin University of Medical Sciences, Iran \\ ${ }^{5}$ Department of Oral and Maxillofacial Surgery, School of Dentistry, Shahid Beheshti University of Medical Sciences, Tehran, Iran \\ A - research concept and design; $\mathrm{B}$ - collection and/or assembly of data; $\mathrm{C}$ - data analysis and interpretation; \\ $D$ - writing the article; $E$ - critical revision of the article; $F$ - final approval of the article
}

Address for correspondence

Mona Akbari

E-mail:mona_akbari91@yahoo.com

Funding sources

None declared

Conflict of interest

None declared

Acknowledgements

The authors are greatly thankful to the staff members

of Sina Hospital in Tehran, Iran, for their utmost cooperation.

Received on July 18, 2019

Reviewed on July 31,2019

Accepted on September 25, 2019

Published online on March 31, 2020

Cite as

Mortazavi H, Akbari M, Sahraian MA, Jahromi AA, Shafiei S. Salivary profile and dental status of patients with multiple sclerosis. Dent Med Probl. 2020;57(1):25-29.

doi:10.17219/dmp/112576

D0I

$10.17219 / \mathrm{dmp} / 112576$

Copyright

○ 2020 by Wroclaw Medical University

This is an article distributed under the terms of the

Creative Commons Attribution 3.0 Unported License (CC BY 3.0)

(https://creativecommons.org/licenses/by/3.0/)

\section{Abstract}

Background. Multiple sclerosis (MS) is a chronic autoimmune disease of the central nervous system. The MS patients may display biochemical changes in their cerebrospinal fluid, peripheral blood and saliva. Since the salivary profile plays a critical role in maintaining oral health and function, the analysis of saliva in the MS patients would be beneficial to prevent oral diseases, such as dental caries.

Objectives. The aim of this study was to evaluate the dental status and salivary profile of the MS patients.

Material and methods. The study involved 25 MS patients and 25 healthy controls who were examined with regard to the calcium and phosphorus level, pH and flow rate of saliva as well as the decayed, missing and filled teeth (DMFT) index for permanent first molars. Student's $t$-test, the $x^{2}$ test and the Mann-Whitney test were utilized to compare the study groups.

Results. Significantly lower salivary flow rates were observed in the MS patients as compared to the controls. The salivary calcium and phosphorus levels were significantly higher in the case group during the first 6 years of the disease and 6-11 years after the onset of the disease, respectively, in comparison with the controls; however, there was no significant difference between the groups in terms of pH. The DMFT index for permanent first molars was higher in the MS patients than in the healthy controls, but not significantly. The number of carious and missing permanent first molars was significantly higher in the MS patients.

Conclusions. Multiple sclerosis appears to significantly change the salivary profile and dental status of the patients.

Key words: multiple sclerosis, DMFT, salivary profile

Słowa kluczowe: stwardnienie rozsiane, DMFT, profil ślinowy 


\section{Introduction}

Multiple sclerosis (MS) is a chronic autoimmune inflammatory demyelinating disease which affects the central nervous system. It is prevalent all around the world, with lowrate prevalence in Eastern Asia and sub-Saharan Africa, and higher levels in North America and Europe. ${ }^{1}$ The onset is mostly between the age of 20 and 40 years (range: 10-60 years), with a female predilection (a female-to-male ratio of 1.4). ${ }^{2}$ The main environmental-related risk factor for MS is, apart from genetics, the Epstein-Barr virus infection, especially if it occurs during adulthood and is symptomatic. Previous studies have shown that smoking as well as the calcium and vitamin D deficiencies can be identified as risk factors for MS, but the role of stress, traumatic events, vaccines, and allergies have not yet been clarified. ${ }^{1,3}$ The MS patients may display biochemical abnormalities in their cerebrospinal fluid, peripheral blood and saliva. ${ }^{3}$ The physical and chemical properties of saliva play a key role in maintaining the health and functioning of the oral cavity. Recent studies show that there is a meaningful relationship between oral lesions and the salivary electrolytes, flow rate and $\mathrm{pH}^{3}$ There is limited information about the salivary profile and orodental status of patients with MS. ${ }^{4}$ In addition to the main symptoms of the disease, spasms, fatigue, tremor, depression, and progressive disability impact the individual's ability to maintain oral health, cope with dental treatment and access dental services. Furthermore, many of the medications used to manage the disease and its related problems, such as psychological disorders, reported in about half of all patients, are potentially capable of causing xerostomia and associated oral abnormalities. .,6 $^{5}$

The main aim of this study was to evaluate the salivary profile and dental status of the MS patients as compared to the healthy controls. In addition, all salivary and dental variables were compared among the MS patients in 3 subgroups according to disease duration.

\section{Material and methods}

\section{Patient selection}

In this descriptive study, $25 \mathrm{MS}$ patients (the case group) and 25 age- and sex-matched healthy controls (the control group) with a mean age of $35.74 \pm 9.45$ years (range: $12-54$ years), and 18 females (72\%) and 7 males (28\%) in each of the groups were studied with regard to the salivary calcium, phosphorus, $\mathrm{pH}$, and flow rate as well as the decayed, missing and filled teeth (DMFT) index for permanent first molars. The case group was recruited from among patients at the Neurology Department of Sina Hospital in Tehran, Iran, and the control group was selected from the hospital staff or patient companions from July to December, 2017. The exclusion criteria for the case group were pregnancy, alcohol dependency and oral lesions. Since almost all MS patients use supplemental drugs, this item was not considered an exclusion criterion in this group. The same criteria were applied to the control group, but those with a history of medication intake or use of supplements in the previous 6 months were excluded from this group. In addition, tooth brushing at least once a day was an inclusion criterion for both groups. Participants were informed of the aim of the study, and written consent was obtained from all participants.

This article was extracted from one of the author's (H.M.) general dentistry dissertation, registered in 2017. The reference number confirming the consent of the local bioethics commission (School of Dentistry of Shahid Beheshti University of Medical Sciences in Tehran, Iran) is 0310/303.

\section{Salivary collection, flow rate and $\mathrm{pH}$}

Unstimulated whole saliva was collected from both groups according to the method described by Navazesh and Kumar. ${ }^{7}$ The participants were asked to refrain from drinking, eating, smoking, and tooth brushing for about $2 \mathrm{~h}$ before sampling. One minute after rinsing their mouths with tap water, the participants were asked to swallow all their oral fluid, and then expectorate $5 \mathrm{~mL}$ of their whole saliva into a plastic tube. The saliva samples were collected between 10 and $12 \mathrm{am}$. The samples were centrifuged at $3,800 \mathrm{~g}$ for $10 \mathrm{~min}$, and then stored at $-70^{\circ} \mathrm{C}$ for later analysis. The salivary flow rate was measured in $\mathrm{mL} / \mathrm{min}$ and the salivary $\mathrm{pH}$ was determined by means of an electronic $\mathrm{pH}-$ meter (pH600; Milwaukee Instruments, Szeged, Hungary).

\section{Calcium and phosphorus detection}

The salivary calcium and phosphorus levels were determined using commercially available kits (Darman Faraz Kave Co., Isfahan, Iran and Pars Azmoon Co., Karaj, Iran, respectively) for a spectrophotometric assay. Since Khan demonstrated that the DMFT index for permanent first molars can serve as an indicator of dental caries, ${ }^{8}$ we used it to evaluate the dental status of both study groups. In this index, D stands for untreated decayed teeth, $M$ indicates missing teeth and $F$ stands for filled teeth; fullcoverage crowns and pontics in dental bridges are considered as $F$ and $M$, respectively. ${ }^{9}$ In addition, the members of the case group were divided into 3 subgroups according to their disease duration as follows: $<6$ years; $6-11$ years; and $>11$ years, and the study variables were compared among them.

\section{Statistical analysis}

The data was analyzed using PASW Statistics for Windows, v. 18 (SPSS Inc., Chicago, USA). Student's $t$-test, the $X^{2}$ test and the Mann-Whitney test were utilized to compare the study groups, and $p$-values $<0.05$ were considered statistically significant. 


\section{Results}

In total, 50 individuals were studied with a mean age of $35.74 \pm 9.45$ years (range: $12-54$ years). There was no significant difference in the mean age of the case group (35.80 \pm 9.58 years) and the control group (35.68 \pm 9.51 years). Out of 25 individuals in each group, 18 (72\%) were females and 7 (28\%) males. In the case group, the duration of the disease varied from 21 days to 18 years, with a mean duration of $7.72 \pm 4.48$ years. The saliva analysis showed a significantly lower flow rate in the MS patients than in the controls $(p<0.001)$ (Table 1$)$. There was no significant difference between the 2 groups in terms of $\mathrm{pH}$ $(p=0.138)$. The salivary calcium and phosphorus levels were significantly higher in the case group than in the controls ( $p=0.011$ and $p=0.020$, respectively) (Table 1 ). With regard to the dental status, the DMFT index scores for permanent first molars were higher among the MS patients than in the healthy controls, but this difference was not statistically significant $(p=0.452)$. However, except for the filled teeth, the number of carious and missing permanent first molars was significantly higher in the case group than in the control group $(p=0.038$ and $p=0.019$, respectively) (Table 1 ). As shown in Table 2, the salivary calcium and phosphorus levels were significantly higher in the MS patients than in the healthy controls during the first 6 years of the disease $(p=0.016)$ and $6-11$ years after the onset of the disease $(p=0.019)$, respectively. The salivary flow rate was significantly lower in the MS patients than in the controls during the entire course of the disease (Table 2). In addition, the duration of the disease was not associated with any significant differences in terms of dental status parameters $(p>0.05)$ (Table 3$)$.

\section{Discussion}

Multiple sclerosis is the most common cause of neurological disability in young people and it is most frequently observed in the $2^{\text {nd }}-4^{\text {th }}$ decades of life. ${ }^{1-3}$ In the present study, the mean age of the MS patients was

Table 1. Salivary parameters and the decayed, missing and filled teeth (DMFT) index

\begin{tabular}{|l|c|c|c|}
\multicolumn{1}{|c|}{ Variable } & Case group & Control group & $p$-value \\
\hline Flow rate $[\mathrm{mL} / \mathrm{min}]$ & $0.47 \pm 0.35$ & $1.17 \pm 0.74$ & $<0.001$ \\
pH & $6.66 \pm 0.60$ & $6.42 \pm 0.51$ & 0.138 \\
Calcium $[\mathrm{mmol} / \mathrm{L}]$ & $1.46 \pm 0.90$ & $0.94 \pm 0.26$ & 0.011 \\
Phosphorus $[\mathrm{mmol} / \mathrm{L}]$ & $3.93 \pm 1.26$ & $3.01 \pm 0.55$ & 0.020 \\
DMFT (n) & $2.64 \pm 1.43$ & $2.16 \pm 1.31$ & 0.452 \\
D (n) & $0.56 \pm 0.76$ & $0.16 \pm 0.37$ & 0.038 \\
M (n) & $1.12 \pm 1.26$ & $0.20 \pm 0.50$ & 0.019 \\
F (n) & $0.96 \pm 1.20$ & $1.80 \pm 1.32$ & 0.147 \\
\hline
\end{tabular}

Data presented as mean \pm standard deviation (SD).
Table 2. Salivary parameters in the case subgroups with different disease duration and in the controls

\begin{tabular}{|c|c|c|c|c|c|}
\hline \multirow{2}{*}{\multicolumn{2}{|c|}{ Variable }} & \multicolumn{3}{|c|}{$\begin{array}{l}\text { Case subgroups } \\
\text { (according to disease duration) }\end{array}$} & \multirow{2}{*}{$\begin{array}{l}\text { Control } \\
\text { group }\end{array}$} \\
\hline & & $<6$ years & 6-11 years & $>11$ years & \\
\hline \multirow{2}{*}{$\begin{array}{l}\text { Flow rate } \\
{[\mathrm{mL} / \mathrm{min}]}\end{array}$} & mean $\pm S D$ & $0.44 \pm 0.31$ & $0.48 \pm 0.41$ & $0.48 \pm 0.38$ & \multirow{2}{*}{$1.17 \pm 0.7$} \\
\hline & $p$-value & 0.010 & 0.020 & 0.010 & \\
\hline \multirow{2}{*}{$\mathrm{pH}$} & mean $\pm S D$ & $6.81 \pm 0.53$ & $6.43 \pm 0.77$ & $6.72 \pm 0.50$ & \multirow{2}{*}{$6.42 \pm 0.51$} \\
\hline & $p$-value & 0.242 & 1.000 & 0.419 & \\
\hline \multirow{2}{*}{$\begin{array}{l}\text { Calcium } \\
{[\mathrm{mmol} / \mathrm{L}]}\end{array}$} & mean $\pm S D$ & $1.73 \pm 0.85$ & $1.36 \pm 0.94$ & $1.31 \pm 0.96$ & \multirow{2}{*}{$0.94 \pm 0.26$} \\
\hline & $p$-value & 0.016 & 0.330 & 0.399 & \\
\hline \multirow{2}{*}{$\begin{array}{l}\text { Phosphorus } \\
{[\mathrm{mmol} / \mathrm{L}]}\end{array}$} & mean $\pm S D$ & $3.85 \pm 1.25$ & $4.16 \pm 1.29$ & $3.78 \pm 1.38$ & \multirow{2}{*}{$3.01 \pm 0.55$} \\
\hline & $p$-value & 0.110 & 0.019 & 0.138 & \\
\hline
\end{tabular}

Table 3. The DMFT index scores in the case subgroups with different disease duration and in the controls

\begin{tabular}{|c|c|c|c|c|c|}
\hline Variable & Group & Mean $\pm S D$ & $\begin{array}{l}\text { Median } \\
\text { (P50) }\end{array}$ & $\begin{array}{c}\text { IQR } \\
\text { (P25-P75) }\end{array}$ & $p$-value \\
\hline \multirow{4}{*}{$\begin{array}{l}\text { DMFT } \\
\text { for first } \\
\text { molars (n) }\end{array}$} & control & $2.16 \pm 1.31$ & 2.00 & $1.00-3.00$ & - \\
\hline & $<6$ years & $3.00 \pm 0.92$ & 3.00 & $2.00-4.00$ & \multirow{3}{*}{0.457} \\
\hline & $6-11$ years & $2.13 \pm 1.45$ & 2.50 & $0.50-2.50$ & \\
\hline & $>11$ years & $2.44 \pm 1.59$ & 3.00 & $1.00-4.00$ & \\
\hline \multirow{4}{*}{$D(n)$} & control & $0.16 \pm 0.37$ & 0.00 & $0.00-0.00$ & - \\
\hline & $<6$ years & $1.00 \pm 0.92$ & 1.00 & $0.00-2.00$ & 0.075 \\
\hline & $6-11$ years & $0.25 \pm 0.46$ & 0.00 & $0.00-0.75$ & 1.000 \\
\hline & $>11$ years & $0.44 \pm 0.72$ & 0.00 & $0.00-1.00$ & 1.000 \\
\hline \multirow{4}{*}{$M(n)$} & control & $0.20 \pm 0.50$ & 0.00 & $0.00-0.00$ & - \\
\hline & $<6$ years & $1.00 \pm 1.06$ & 1.00 & $0.00-2.00$ & 0.294 \\
\hline & $6-11$ years & $1.00 \pm 1.19$ & 0.50 & $0.00-2.00$ & 0.321 \\
\hline & $>11$ years & $1.33 \pm 1.58$ & 1.00 & $0.00-2.50$ & 0.057 \\
\hline \multirow{4}{*}{$F(n)$} & control & $1.81 \pm 0.32$ & 2.00 & $0.50-2.00$ & - \\
\hline & $<6$ years & $1.12 \pm 1.45$ & 0.50 & $0.00-2.00$ & \multirow{3}{*}{0.147} \\
\hline & $6-11$ years & $1.00 \pm 1.41$ & 0.00 & $0.00-2.75$ & \\
\hline & $>11$ years & $0.77 \pm 0.83$ & 1.00 & $0.00-1.50$ & \\
\hline
\end{tabular}

IQR - interquartile range.

$35.80 \pm 9.58$ years, which is consistent with recent reports by Etemadifar et al. ${ }^{10}$ According to Hernán et al., a higher risk of MS has been reported among individuals with a history of oc-currence of measles and other common childhood diseases during adolescence. ${ }^{11}$ Multiple sclerosis can be found at any age, but it is referred to as 'earlyonset MS' when the first presentation of clinical symptoms occurs before the age of 21, whereas 'late-onset MS' refers to cases in which the first presentation of clinical symptoms occurs after the age of 50 years. ${ }^{12}$

In this study, more than $70 \%$ of the MS patients were females, which is comparable to previous studies conducted in Iran and other countries. ${ }^{1,2,10,13}$ It is believed that there are genetic mechanisms for sex differences in MS. The epigenetic modifications of DNA may be caused by hormonal or environmental stimuli, which differ between 
males and females. Males and females might have different responses to the same environmental stimuli, such as sun exposure and vitamin D supplements. Accordingly, higher levels of vitamin D decrease the incidence of MS more in females than in males. It has also been noted that the $\mathrm{X}$ chromosome may play a direct role in autoimmunity; therefore, the presence of $2 \mathrm{X}$ chromosomes increases susceptibility to autoimmune encephalomyelitis. Furthermore, the $\mathrm{X}$ chromosome inactivation in females may be skewed, resulting in the over-expression of MS susceptibility genes in women. On the other hand, male sex hormones, such as testosterone, have a protective role in autoimmunity.

Our results show that the MS patients had a significantly lower salivary flow rate than the healthy controls. Similarly, in their 2 recent studies, Cockburn et al. demonstrated that xerostomia was the most common side effect of the medications used to treat MS and related problems, which is followed by dysgeusia, dysphagia, oral ulcers, and sinusitis. ${ }^{14,15}$ Further, Sandberg-Wollheim et al. concluded that MS and primary Sjögren's syndrome might coexist in the same individual. ${ }^{16}$ In accordance with this hypothesis, Miró et al. and de Seze et al. reported respectively that $3.1 \%$ and $16.6 \%$ of the MS patients had the clinical evidence of Sjögren's syndrome. ${ }^{17,18}$ However, the relationship between MS and primary Sjögren's syndrome is ambiguous, and primary Sjögren's syndrome is not more common among the MS patients than expected in the general population. ${ }^{16,17}$

In the present study, there was no significant difference between the MS patients and the controls in terms of the salivary $\mathrm{pH}$. We did not find a similar study in this regard in the literature to compare our findings with. Normal saliva $\mathrm{pH}$ ranges from 6.2 to 7.6 , with a mean of 6.7 . The resting $\mathrm{pH}$ of the mouth does not usually fall below 6.3 and $\mathrm{pH}$ in the oral cavity is normally maintained near neutrality (6.7-7.3) by the buffering capacity of saliva. ${ }^{19}$

The salivary calcium and phosphorus levels in our study were found to be significantly higher in the MS patients than in the controls. There is limited information in the literature about the alterations of these factors in the salivary samples of the MS patients in comparison with blood samples. In a case report, Marcus et al. described severe hypercalcemia following vitamin $\mathrm{D}$ supplementation in a patient with $\mathrm{MS} .^{20}$ It is common practice to prescribe high-dose cholecalciferol for the MS patients because of its possible role in immunomodulation and relapse rate reduction. However, cholecalciferol may increase serum calcium, and there seems to be an additive effect in patients who simultaneously use calcium supplements as well. An elevated level of salivary calcium may be related to a greater degree of bone loss and a lower mineral density of bones, as bone loss can cause the release of calcium into blood, and then saliva. ${ }^{21}$ Gupta et al. concluded that MS was associated with increased osteoporosis. ${ }^{22}$ A reduced mechanical load on the bones (offsetting gravity) and physical inactivity are major factors for osteoporosis in MS. Medications such as glucocorticoids and anticonvulsants may be additional factors leading to a lower bone density in this group of patients. The same findings were also reported by Kampman et al. ${ }^{23}$ In addition, chronic secondary hyperparathyroidism in the MS patients stimulates renal calcium reabsorption and bone resorption to elevate the blood calcium levels. ${ }^{24}$ According to KubickaBaczyk et al., the MS patients had a significantly higher level of serum parathormone than the controls. ${ }^{25}$ In their study, daily urine calcium excretion was lower in the patients than in the healthy controls; the serum phosphorus, calcium and alkaline phosphatase levels were higher in the patients than in the controls, but these differences were not statistically significant. ${ }^{25}$ In contrast to all the aforementioned studies, Chałas found that the calcium levels in the saliva of the MS patients were significantly lower than in the healthy controls. ${ }^{3}$ This difference may be related to different patient characteristics, such as the duration of the disease, the type of medications taken, study sample size, the methods of calcium detection, and different inclusion and exclusion criteria according to the study design. Furthermore, Mohammad Shirazi et al. showed that a daily intake of phosphorus, potassium, manganese, and copper in Iranian MS patients was higher than the standard recommended amounts. ${ }^{26}$

In terms of the dental status, the DMFT index scores did not differ significantly between the patients with MS and the healthy controls. However, the number of decayed and missing teeth was significantly higher in the patients than in the healthy controls. The same findings were also reported by Santa Eulalia-Troisfontaines et al. and Kovac et al. ${ }^{4,27}$ As in this study, Kovac et al. found that the number of decayed and missing teeth was higher, but the number of filled teeth was significantly lower in the MS patients than in the controls. ${ }^{27}$ In contrast, McGrother et al. found significantly higher DMFT index scores in the MS patients as compared to the healthy controls, and the number of filled and missing teeth was also higher in the patients than in the controls. ${ }^{28}$

In a recent study by Hatipoglu et al., the relationship between the different disability states of the MS patients, as determined by the expanded disability status scale, and dental-periodontal measures was evaluated. ${ }^{29}$ Those authors found that patients with greater physical disabilities had higher numbers of missing teeth, higher plaque and gingival indices, and higher periodontal probing depth scores than patients with lesser physical disabilities. ${ }^{29}$ According to the aforementioned studies, it seems that patients with MS mostly prefer to extract their decayed teeth rather than to restore them.

Multiple sclerosis is a prime example of systemic diseases requiring multidisciplinary care. The MS care units usually include a variety of medical specialists, such as neurologists, physical therapists, speech therapists, psychologists, social workers, nurses, and - recently - lawyers. However, 
there are few reports in the literature on dental care as part of the interdisciplinary therapy for the MS patients. Fragoso et al. found that the MS patients had very poor oral hygiene, and also pointed out that despite recommendations for an interdisciplinary approach for the MS patients, dentists are not usually included in this professional health group. ${ }^{30}$ Therefore, oral pathologies in these patients often remain undetected, underassessed or overlooked.

\section{Conclusions}

The present study found that due to the quality and quantity of changes in the saliva of patients with MS, the dental caries and loss of permanent first molars were more frequent in the MS patients.

\section{ORCID iDs}

Hamed Mortazavi (1) https://orcid.org/0000-0002-0778-5299

Mona Akbari (1) https://orcid.org/0000-0001-6648-1407

Mohammad Ali Sahraian (1) https://orcid.org/0000-0002-3224-8807

Ali Alborzi Jahromi (1) https://orcid.org/0000-0002-7133-3510

Shervin Shafiei (1) https://orcid.org/0000-0002-0415-4678

\section{References}

1. Leray E, Moreau T, Fromont A, Edan G. Epidemiology of multiple sclerosis. Rev Neurol (Paris). 2016;172(1):3-13.

2. Gallud L, Bagan JV, Cervelló A, Jiménez Y, Poveda R, Gavalda C. Multiple sclerosis as first manifestation in oral and facial area: Presentation of four cases. Med Oral Patol Oral Cir Bucal. 2006;11(2):E141-E145.

3. Chałas R. Calcium and potassium saliva concentration in patients with multiple sclerosis. Acta Stomatol Croat. 2009;43(1):34-38.

4. Santa Eulalia-Troisfontaines E, Martínez-Pérez EM, MiegimolleHerrero M, Planells-Del Pozo P. Oral health status of a population with multiple sclerosis. Med Oral Patol Oral Cir Bucal. 2012;17(2):e223-e227.

5. Feinstein A. Multiple sclerosis and depression. Mult Scler. 2011;17(11):1276-1281.

6. Fiske J, Griffiths J, Thompson S. Multiple sclerosis and oral care. Dent Update. 2002;29(6):273-283.

7. Navazesh M, Kumar SK. Measuring salivary flow: Challenges and opportunities. J Am Dent Assoc. 2008;139(Suppl):35S-40S.

8. Khan AA. The permanent first molar as an indicator for predicting caries activity. Int Dent J. 1994;44(6):623-627.

9. Becker T, Levin L, Shochat T, Einy S. How much does the DMFT index underestimate the need for restorative care? J Dent Educ. 2007;71(5):677-681.

10. Etemadifar M, Sajjadi S, Nasr Z, et al. Epidemiology of multiple sclerosis in Iran: A systematic review. Eur Neurol. 2013;70(5-6):356-363.

11. Hernán MA, Zhang SM, Lipworth L, Olek MJ, Ascherio A. Multiple sclerosis and age at infection with common viruses. Epidemiology. 2001;12(3):301-306.

12. Polliack ML, Barak Y, Achiron A. Late-onset multiple sclerosis. J Am Geriatr Soc. 2001;49(2):168-171.

13. Harbo HF, Gold R, Tintoré M. Sex and gender issues in multiple sclerosis. Ther Adv Neurol Dis. 2013;6(4):237-248.

14. Cockburn N, Pateman K, Taing MW, Pradhan A, Ford PJ. Managing the oral side-effects of medications used to treat multiple sclerosis. Aust Dent J. 2017;62(3):331-336.

15. Cockburn N, Pradhan A, Taing MW, Kisely S, Ford PJ. Oral health impacts of medications used to treat mental illness. J Affect Disord. 2017:223:184-193.

16. Sandberg-Wollheim M, Axéll T, Hansen BU, et al. Primary Sjögren's syndrome in patients with multiple sclerosis. Neurology. 1992;42(4):845-847.

17. Miró J, Peña-Sagredo JL, Berciano J, Insúa S, Leno C, Velarde R. Prevalence of primary Sjögren's syndrome in patients with multiple sclerosis. Ann Neurol. 1990;27(5):582-584.
18. de Seze J, Devos D, Castelnovo G, et al. The prevalence of Sjögren syndrome in patients with primary progressive multiple sclerosis. Neurology. 2001;57(8):1359-1363.

19. Baliga S, Muglikar S, Kale R. Salivary pH: A diagnostic biomarker. JIndian Soc Periodontol. 2013;17(4):461-465.

20. Marcus JF, Shalev SM, Harris CA, Goodin DS, Josephson SA. Severe hypercalcemia following vitamin $D$ supplementation in a patient with multiple sclerosis: A note of caution. Arch Neurol. 2012;69(1):129-132.

21. Arbabi-Kalati F, Sandoghi M, Moradi M, Salimi S. Relationship between bone density and salivary calcium in women with rheumatoid arthritis undergoing corticosteroid therapy. Dent Clin Exp J. 2016; [in press]: e11432.

22. Gupta S, Ahsan I, Mahfooz N, Abdelhamid N, Ramanathan M, Weinstock-Guttman B. Osteoporosis and multiple sclerosis: Risk factors, pathophysiology, and therapeutic interventions. CNS Drugs. 2014;28(8):731-742.

23. Kampman MT, Eriksen EF, Holmøy T. Multiple sclerosis, a cause of secondary osteoporosis? What is the evidence and what are the clinical implications? Acta Neurol Scand. 2011;124(Suppl 191):44-49.

24. van Amerongen BM, Feron F. Effect of high-dose vitamin D3 intake on ambulation, muscular pain and bone mineral density in a woman with multiple sclerosis: A 10-year longitudinal case report. Int J Mol Sci. 2012;13(10):13461-13483.

25. Kubicka-Baczyk K, Labuz-Roszak B, Pierzchala K, Adamczyk-Sowa M, Machowska-Majchrzak A. Calcium-phosphate metabolism in patients with multiple sclerosis. J Endocrinol Invest. 2015;38(6):635-642.

26. Mohammad Shirazi M, Taleban F, Ghafarpoor M. Comparison of micronutrient intake in multiple sclerosis patients in Tehran with the recommended doses. Iran J Epidemiol. 2006;2(1-2):27-34.

27. Kovac Z, Uhac I, Buković D, Cabov T, Kovacević D, Grzić R. Oral health status and temporomandibular disorders in multiple sclerosis patients. Coll Antropol. 2005;29(2):441-444.

28. McGrother CW, Dugmore C, Phillips MJ, Raymond NT, Garrick P, Baird WO. Multiple sclerosis, dental caries and fillings: A casecontrol study. Br Dent J. 1999;187(5):261-264.

29. Hatipoglu H, Canbaz Kabay S, Gungor Hatipoglu M, Ozden H. Expanded disability status scale-based disability and dental-periodontal conditions in patients with multiple sclerosis. Med Princ Pract. 2016;25(1):49-55.

30. Fragoso YD, Carvalho Alves HH, Carvalho Alves L, Carvalho Alves $\mathrm{N}$, Siqueira de Andrade CM, Finkelsztejn A. Dental care in multiple sclerosis: An overlooked and under-assessed condition. J Disab Oral Health. 2010;11(2):53-56. 